Cómo citar este artículo en Chicago: Balibar, Étiene. "De la violencia como antipolítica a la política como antiviolencia” Traducido por Juan David Almeyda Sarmiento. Escritos 29, no. 63 (2021): 355-368. doi: http://doi.org/10.18566/escr.v29n63.a10

Fecha de recepción: 29.06 .2021

Fecha de aceptación: 09.11.2022

\title{
De la violencia como antipolítica a la política como antiviolencia ${ }^{1}$
}

\author{
From Violence as Anti-Politics to Politics as Anti-Violence
}

\author{
Étiene Balibar ${ }^{2}$ \\ Traducido por Juan David Almeyda Sarmiento ${ }^{3}$
}

\begin{abstract}
RESUMEN
Este artículo analiza la violencia en su relación intrínseca con la política. Esta conjunción de política y violencia no es solo una característica especial de nuestra experiencia histórica, sino que más bien nunca podrá separarse de esta última, aunque siempre desde distintas formas y en diferentes grados. A partir de situaciones que encarnan la violencia extrema, o la crueldad, y contrastándolas con una política de civilidad, este artículo sostiene que, si queremos definir las condiciones y los objetivos de la política, no basta con ser conscientes de la violencia o en verla como un problema central de la política. Lo que necesitamos es una nueva base para la política, que surja de una consideración de la violencia extrema. La violencia extrema, por tanto, no es una cuestión entre otras para la política, sino que es la cuestión donde está en juego la posibilidad o la imposibilidad de la política.
\end{abstract}

Palabras clave: Violencia; Política; Civismo; Crueldad

1 Una versión anterior de este artículo fue presentada (en francés) en la Conferencia Internacional "Violence, Politique, Exil/Dés-éxil dans le monde d'aujourd'hui”, celebrada en Estambul, organizada por la Université Galatasaray y el Collège International de Philosophie Paris, del 7 al 10 de mayo de 2014 y, posteriormente (en inglés) en el taller de la Escuela de Análisis Cultural de Âmsterdam "Diseccionando la violencia" en la Universidad de Âmsterdam, del 4 al 6 de abril de 2018, y en la conferencia "Órdenes de la violencia" en la Universidad Americana de París, del 9 al 10 de abril de 2018. Artículo publicado originalmente con el título "From Violence as Anti-Politics to Politics as Anti-Violence" en el volumen 3, número 3 (2020), pp. 384-399 de la revista Critical Times. https://doi.org/10.1215/26410478-8662288. Un agradecimiento especial a la revista Critical Times y a Étienne Balibar por otorgar la autorización correspondiente para la publicación de la traducción.

2 Profesor emérito de Filosofía Moral y Política en la Universidad de Nanterre y de Humanidades en la Universidad de California, Irvine.

3 Maestrando en Filosofía en la Universidad Industrial de Santander, Colombia. Profesor de la Escuela de Filosofía de la misma universidad. Correo electrónico: juanalmeyda96@gmail.com. 


\begin{abstract}
This article discusses violence in its intrinsic relationship to politics. This conjunction of politics and violence is not just a special feature of our historical experience; rather it can never be separated from it, albeit with distinct forms and to different degrees. Starting from situations embodying extreme violence, or cruelty, and contrasting them with a politics of civility, this article argues that if we want to define the conditions and the goals of politics, it is not enough to just be mindful of violence, or to see it as a central problem for politics. What we need is a new foundation for politics, arising from the consideration of extreme violence. Extreme violence, therefore, is not one question among others for politics; it is the question where the possibility or impossibility of politics is at stake.
\end{abstract}

Keywords: Violence; Politics; Civility; Cruelty

$\mathrm{M}$ i objeto de estudio es la violencia en su relación intrínseca con la política, lo cual implica tanto la "ciudad" como el espacio público. Juntos, ambos lados, le ponen límites a la violencia, pero también se entrometen en ella. Como muchos de nosotros, me di cuenta de que esta conjunción de política y violencia no es solo una característica especial de nuestra experiencia histórica; más bien, nunca podrá separarse de ella, aunque sea con distintas formas y en diferentes grados. Como escribió una vez mi maestro Louis Althusser, este tipo de experiencia requiere "pensar en los extremos" (penser aux extrêmes). ${ }^{4}$ Esto último no es solo una elección metodológica, también es la necesidad impuesta por el tema mismo. ¿Cuáles son estos "extremos"? Son situaciones que encarnan la violencia extrema, para las cuales en una colección previa de ensayos elegí el nombre de "crueldad", que contrasta hipotéticamente con una política de civilidad. ${ }^{5} \mathrm{Mi}$ tesis sostiene que, si queremos definir las condiciones y los objetivos de la política, no basta con estimar la violencia o verla como un problema central de la política. Lo que necesitamos es una nueva base política que surja de la consideración de la violencia extrema. La violencia extrema, por tanto, no es una cuestión entre otras para la política, también es la cuestión en donde está en juego la posibilidad o la imposibilidad de la política y, por ende, es una cuestión de vida o muerte. Esto no quiere decir que este tema sustituirá a cualquier otra cuestión de economía o cultura, derecho o justicia; pero sí debe "sobredeterminar" todos estos asuntos, y revelar las determinaciones antinómicas que las hacen, en cierto sentido, como propuso Hannah Arendt, "infundadas".

Sin embargo, antes de explorar más esta tesis, conviene hacer algunas observaciones preliminares. Quiero indicar las distinciones epistemológicas y semánticas que creo que se requieren. Primero, deseo rechazar una tesis que los filósofos políticos a menudo consideran crucial, a saber: la afirmación de que la política y la violencia son términos antitéticos, que son entre sí lo que un fin racional es a un obstáculo para su realización, porque la política está en el lado del derecho y la violencia es una perversión o un elemento de irracionalidad. Por medio de Maquiavelo y varios otros (Weber, en particular), sostengo que la violencia no es lo otro de la política, lo que significaría que la política, de hecho, tiene un lugar y se organiza fuera del ámbito de la violencia. Esto no implica que la política sea simplemente la expresión de

4 Louis Althusser, "Defensa de tesis en Amiens", en Posiciones. Traducción de Ricardo Pochtar (Barcelona: Anagrama, 1977), 133.

5 Étienne Balibar, Violence and Civility: On the Limits of Political Anthropology. Traducido por G. M. Goshgarian (Nueva York: Columbia University Press, 2014).

6 Véase la discusión sobre el "abismo de la libertad” en Hannah Arendt, La vida del espíritu: El pensar, la voluntad y el juicio en la filosofía y en la política. Traducido por Ricardo Montoro y Fernando Vallespín (Madrid: Centro de Estudios Constitucionales, 1984), 485. 
la violencia, o, para decirlo en términos clausewitzianos invertidos, como una vez propuso Foucault, que la política es "la continuación de la violencia [la guerra] por otros medios". Esto significa, sin embargo, que siempre que la política intenta utilizar la violencia o transformarla nunca puede esperar trascender el reino de la violencia, o permanecer ajeno a sus efectos, bajo la protección de una esencia ideal. Están en juego muchas cuestiones de principio, de las cuales considero solo algunos aspectos.

Primero están las cuestiones antropológicas- tal vez incluso teológicas. Si es cierto que la violencia condena a la política, esto podría deberse a que la política siempre se desarrolla en el ámbito del mal, testimoniando la condición de abandono en la que la especie humana y las sociedades en las que se divide se hunden como consecuencia de su pecado original. Este tipo de representación se puede secularizar y dar lugar a una noción de finitud violenta concebida como una condición antropológica general: la "guerra de todos contra todos" hobbesiana, a la que volveré. La cadena de consecuencias es más o menos fatal, pero nunca se puede evitar del todo, ya que esta condición originaria nos lleva de la vulnerabilidad al sometimiento, al poder y su uso excesivo, a la violencia cíclica, a la crueldad. Para que exista un punto de detención, reversión o bifurcación, debe, por tanto, ser concebido (como en Hobbes y otros, hasta Weber) como una institución o una invención artificial que vuelve la violencia contra sí misma, en forma de contraviolencia. Esto último aparece como un equivalente pragmático de la idea teológica del mal en el ámbito de la historia y la experiencia. Sin embargo, la historia y la experiencia política son suficientes para hacernos una pregunta diferente, la relativa a la contaminación de los "fines" de la política por sus "medios". Oficialmente, los fines de la política, aunque no sean del todo "puros", son siempre nobles: lo que anuncian es justicia y paz, que como tales se oponen a la violencia. Por el contrario, los medios de la política pueden implicar la necesidad de implementar la violencia, o incluso deben incluirla, porque la justicia y la paz no existen de manera espontánea, o pueden surgir solo si los poderes e intereses existentes se enfrentan en sus propios términos. Pero la experiencia nos enseña que los medios, a su vez, se convierten en fines o los sustituyen cuando parece que estos existen solo en relación con sus medios, o mientras esos medios sean efectivos. Sobre todo, y esta fue una lección enseñada inequívocamente por Gandhi, significa producir una transformación de los fines a los que se aplican dichos medios: estos últimos condicionan o "crean" a los sujetos que los implementan a su propia "imagen". Así, surgen individuos violentos. Esto es lo que me lleva a afirmar que la violencia no puede ser simplemente la otra cara de la política, a menos que queramos imaginar una política sin autoridad, relaciones de poder, desigualdades, conflictos o intereses, lo que equivaldría a una política sin política. En el proceso histórico real de la política, la violencia es siempre parte de las condiciones, así como es parte de los medios y, por tanto, de los fines de la política, porque hay una inmanencia de los fines a los medios, o un devenir inmanente de los fines a los medios, no al revés. En consecuencia, debemos reconocer que existe una ambivalencia fundamental en la política: su relación con la violencia es una consecuencia y una señal de esta ambivalencia. De aquí pasamos a la necesidad de discutir grados y modalidades de violencia en la práctica política. Una fenomenología de la violencia (incluida la violencia extrema) se convierte en una parte crucial de todo concepto genuino de lo político. Y el nombre de civilidad, que invoqué como una posible antítesis de la crueldad, que genéricamente subsume muchas variedades de formas de política "antiviolentas" que buscan controlar los efectos de la violencia en su propia implementación, designará no tanto una antítesis metafísica (un riesgo que percibo siempre en cierta medida en la idea de "no violencia”), sino más bien una contradicción móvil y metamórfica, un conflicto secundario. Por tanto, la

7 Michel Foucault, Defender la sociedad: Curso en el Collège de France (1975-1976). Traducido por Horacio Pons (Buenos Aires: Fondo de Cultura Económica, 2001), 156. 
violencia puede ser "civilizada" o "bárbara". Sin embargo, Soy perfectamente consciente de que hay algo de imposible en esta descripción de un "proceso de violencia civilizadora", no solo porque observamos en la práctica que los que dicen ser los más "civilizados" son de hecho los peores bárbaros (hay que ver toda la historia de la colonización), sino porque la idea va en contra de toda experiencia "normal". Esto dicho lo presento como un punto de partida aporético, empezar a pensar en los extremos, es decir, desplazarse de un extremo a otro, para abordar la política desde el interior de sus contradicciones y transformaciones.

En este punto, necesito hacer una segunda distinción preliminar: la violencia y la violencia extrema son cualitativamente distintas. Una vez más, no se trata de distribuir cada uno de estos en recuadros cuidadosamente separados, utilizando tipologías para garantizar que la "violencia extrema" siga siendo un "estado de excepción" del que estamos protegidos por la política "normal". Por el contrario, mi objetivo es comprender qué ocurre cuando la violencia cae al extremo, la mayoría de las veces de manera inesperada e impredecible, desde dentro de un estado de aparente normalidad. Se debe intentar pensar en una civilización política lo suficientemente poderosa como para evitar que la violencia caiga en sus extremos (o lo que una cierta tradición teológico-política, asociada con Carl Schmitt, llamó una función katechónica). ${ }^{8}$ En Violence and Civility, traté de dar criterios para este límite, que, por supuesto, no son cuantitativos; no se refieren a una medida de sufrimiento o magnitud de destrucción, sino más bien a patrones de situaciones en las que los seres humanos se ven privados de las condiciones bajo las cuales pueden resistir, actuar y manejar su propia vida individual y colectivamente. Sugerí tres de estos criterios:

- Situaciones en las que se aniquila la posibilidad de resistir el poder excesivo o la propia violencia.

- Situaciones en las que se invierten los instintos de autoconservación, los que hacen posible encontrar la vida, aunque sea muy difícil o dolorosa, preferible a la muerte.

- Situaciones de-utilidad radical, no en el sentido limitado que usan los economistas que calculan el valor negativo que representan algunos factores de producción o consumo, sino en el sentido "absoluto" que se refiere a una violencia sin otro "fin" que su propia perpetuación, que aniquila así el uso adecuado de las cosas y las personas.

De hecho, se trata de criterios bastante indeterminados que no son mutuamente independientes. Me centraré en el primero de estos criterios para discutir sus problemas y posibles usos. Hablo de problemas, porque la idea de que toda posibilidad de resistencia se destruye en una situación de extrema opresión o brutalización significa que los agentes, humanos que podrían influir en su propia vida e historia, se transforman en víctimas tan impotentes que se vuelven cosas. Así es como Simone Weil describió la muerte violenta en la guerra en su hermoso ensayo sobre Homero, "La Ilíada o el poema de la fuerza". Pero ¿existe este límite? Incluso si no, tratar de acercarse al punto en el que se volvería pensable puede ser una forma de definir dónde radica realmente la posibilidad y la imposibilidad de la política.

Digo que no podemos estar seguros de que este límite exista por varias razones. Primero, porque resistir el poder excesivo es siempre una capacidad compleja para los humanos, una que combina los instintos que preservan la vida y la capacidad de imaginar el futuro. Es algo que está arraigado tanto en el cuerpo

8 Carl Schmitt, El nomos de la tierra: En el derecho de gentes del "Jus publicum europaeum". Traducido por D. Schilling (Buenos Aires: Struhart, 2005), 41.

9 Simone Weil, "La Ilíada o el poema de la fuerza", en La fuente griega. Traducido por M. E. Valentié (Buenos Aires: Sudamericana, 1961), 13-44. 
como en el alma. La antigua filosofía estoica explicaba que incluso un esclavo sometido a tortura puede conservar en su alma la certeza de que es moralmente libre; pero, a la inversa, Foucault describió el alma como una "prisión del cuerpo". ${ }^{10} \mathrm{Al}$ tratar de describir situaciones de extrema violencia y cómo afectan a sus víctimas, observamos que se llega a un fondo cuando se suprime toda posibilidad de rescate o incluso toda posibilidad de pedir ayuda cuando no hay solidaridad. Pero también observamos que, en cierto sentido, siempre es demasiado pronto para decidir que no llegará ningún rescate, o no habrá combinación de fuerzas internas o externas que, por separado, resistan la violencia y, por tanto, puedan unirse contra ella. Spinoza describió un máximo de compresibilidad en la vida humana, que relacionó con el hecho de que ningún individuo vive una vida completamente aislada, sin el apoyo de los demás. ${ }^{11}$ Esto parece albergar posibilidades invisibles que una política de antiviolencia buscará descubrir y movilizar. Podemos ir un paso más allá, tratando de problematizar un límite simbólico difícil de definir de manera adecuada, pero también imposible de ignorar: muchas de las formas extremas de violencia política, especialmente cuando se basan en procesos de exterminio, no son solo destinadas a suprimir resistencias y vidas reales, también tratan de que la memoria de las víctimas y su posible rehabilitación sea aniquilada en el futuro. Esto plantea la cuestión de la supervivencia y los supervivientes en un sentido amplio (no solo desde el punto de vista de la genealogía). Cuando se trata de destruir grupos humanos, lo que hay que desmantelar es también el recuerdo de lo que han sido, el mero hecho de haber existido alguna vez. Como antes, observamos que no existe una regla general, y podemos especular que lo que es casi posible puede no ser, de hecho, absolutamente cierto. Nuevamente, estamos tratando de identificar los límites y cómo se cruzan.

Los límites son múltiples, de hecho, descubrimos continuamente nuevas figuras que aumentan nuestra sensación de que la violencia extrema concentra en sí misma todas las indeterminaciones que afectan a la propia definición de "política". La violencia extrema afecta a las personas junto con su entorno, sus "seres queridos"; es fundamentalmente micropolítica en el sentido de Foucault. Pero también surge como algo inevitable e incontrolable cuando las masas se movilizan, por debajo o más allá de las estructuras de poder visibles. Para usar palabras de Jacques Rancière, ${ }^{12}$ la violencia extrema genera grandes distribuciones de lo sensible, pero también es lo que revela la ambigüedad misma de la noción de sensible (o perceptible), incluida la distribución de lo que se puede decir y comunicar: algunas de sus formas están claramente hiperrepresentadas en los medios de comunicación, pero tenemos razones para creer firmemente que todo lo que está hiperrepresentado también se disimula o distorsiona, mientras que otras formas de violencia que son más secretas o menos "excepcionales" quedan esencialmente invisibles, son indecibles incluso por sus víctimas. Durante mucho tiempo, esto último fue (y quizá sigue siendo) el caso de la "violencia doméstica", que puede ser extrema. De esta manera abstracta, quiero evocar otro tipo de indeterminación articulada con ambivalencia en situaciones de violencia extrema: siempre es muy difícil saber exactamente dónde puede surgir un umbral de aniquilación para las posibilidades de resistencia, en qué lugar del cuerpo o del alma, dónde en la intimidad del yo o de la vida externa de un sujeto colectivo reside. No hay signo incuestionable que nos permita decidir cuándo simplemente se suprimió

10 Michel Foucault, Vigilar y castigar: Nacimiento de la prisión. Traducido por Aurelio Garzón del Camino (Buenos Aires: Siglo XXI, 2003), 30.

11 Étienne Balibar, Masses, Classes, Ideas: Studies on Politics and Philosophy Before and After Marx (Nueva York: Routledge, 1994), 32-35.

12 Jacques Rancière, El reparto de lo sensible: Estética y política. Traducido por Cristóbal Durán, Helga Peralta, Camilo Rossel, Iván Trujillo y Francisco de Undurraga (Santiago de Chile: LOM, 2009). 
la resistencia en una relación de fuerzas, cuándo la posibilidad de utilizar defensas materiales se ha vuelto demasiado desigual o cuándo debemos hablar de la aceptación de la dominación, el sometimiento a la violencia simbólica, a veces llamada "servidumbre voluntaria" (una expresión realmente problemática). Del mismo modo, los debates actuales sobre el significado del sacrificio y el martirio, por ejemplo, con respecto a los atentados suicidas, también tienen que ver con cómo discernir una forma de resistencia política que está restringida por una "disimetría" absoluta de fuerzas a una caída en la trampa de la violencia mimética que arrastra a víctimas y verdugos al mismo abismo. Doy todos estos ejemplos para mostrar cuán problemática es la distinción, pero no estoy tratando de sugerir que una distinción política entre violencia y violencia extrema no tenga sentido. Creo que es un problema real, pero que carece de una solución general y, por tanto, exige una discusión específica de cada "caso" por actores y espectadores que deben especular sobre su significado. En este espíritu, quiero ahora discutir tres cuestiones que han adquirido cierta urgencia en los lugares donde vivimos y trabajamos.

En primer lugar, quiero discutir la extrema violencia de la globalización capitalista, donde se articulan dos preguntas en una. La primera considera el capitalismo como tal: ¿podemos decir que siempre involucra no solo la violencia que está ligada a la explotación y las diversas formas de sometimiento necesarias para ella, sino también, más allá de esta violencia, una violencia extrema que realmente destruye vidas de seres humanos cuyo trabajo es necesario para su desarrollo (y que, por tanto, también es en cierto sentido autodestructivo)? La segunda pregunta se refiere más precisamente a la globalización: ¿introduce algo que no estaba incluido en el capitalismo histórico, algo que está en exceso con respecto a su lógica? Marx señaló claramente las raíces económicas y las consecuencias sociales de la violencia extrema involucrada en el capitalismo, aunque solo pudo ver algunas de sus consecuencias para la institución de lo político, tal como surgieron en los siglos XIX y XX. Esto último se puede resumir en dos categorías: sobreexplotación y "acumulación primitiva” permanente. En cuanto a la violencia extrema involucrada en la globalización, que tal vez resulte del traspaso de un umbral cualitativo más que de una innovación absoluta, diré que los desarrollos contemporáneos han aumentado y han hecho interdependientes dos procesos: la destrucción del ambiente planetario (que difícilmente puede ser etiquetado como una forma de "destrucción creativa") y la transformación de lo que Marx llamó una "subsunción real" de la fuerza de trabajo bajo la relación social capitalista en lo que yo (con algunos otros) he llamado una "subsunción total" de nuestra existencia, incluso el consumo, la salud, la educación, la vida afectiva, y en general todas las funciones de crianza e individualización del ser humano bajo el capital, especialmente en la forma de su incorporación a los circuitos del capital financiero. Esto es más o menos lo que los economistas neoliberales llaman eufemísticamente el surgimiento del "capital humano" como un amplio campo de inversión. Permítanme agregar algunas palabras más sobre esta transformación. Muchos marxistas (incluido el propio Marx en algunos pasajes) tendían a creer que, cuando la explotación de la fuerza de trabajo toma la forma de trabajo asalariado, lo que significa que tiene lugar una relación contractual y una negociación aparentemente "libre" entre el capitalista y los trabajadores, los primeros deben obedecer ciertas "reglas" de protección del trabajo y el reconocimiento de la persona del trabajador, lo cual impone una medida de "normalidad" en el proceso laboral. Lo cierto es, sin embargo, que tal normalidad existe solo de manera temporal y localizada allí donde las luchas de clases organizadas imponen límites a la explotación, prohíben formas más violentas y obligan al capital a adoptar otras modalidades de desarrollo económico que permitan el acceso de los trabajadores al consumo masivo, a los servicios sociales y a la educación profesional, y que requieren negociación colectiva. Pero en cuanto esta lucha se debilita o se interrumpe, regresan de inmediato formas salvajes de sobreexplotación que amenazan la integridad física y moral de los trabajadores, y adoptan a veces nuevas formas impuestas por las nuevas tecnologías, que no son menos destructivas que las antiguas. Añádase a esto que la sobreexplotación nunca dejó de existir 
en el espacio más amplio de la "economía mundial" capitalista (basta pensar en la violencia extrema que sufren las mujeres y los niños empleados en Bangladés o Pakistán). Esto nos lleva a lo que podría llamarse acumulación primitiva prolongada. Al final del primer volumen de El capital, Marx escribió una sección para descartar los relatos imaginarios del origen del capital en la abstinencia individual, mostrando que resultó históricamente de la expropiación violenta de los pequeños productores, seguida del castigo a los pobres y los nómadas para obligarlos a trabajar en la industria (la "sociedad punitiva" de Foucault). Sin embargo, era común entre los marxistas la sensación de que tales procesos ultraviolentos caracterizaron solo una fase de transición que separaba el "viejo mundo" de las sociedades precapitalistas de las condiciones "normales" de las sociedades burguesas. Los marxistas posteriores, desde Rosa Luxemburgo hasta Immanuel Wallerstein y David Harvey, mostrarían todo lo contrario: esta violencia sangrienta, ya sea enteramente no jurídica, ya sea impuesta legalmente por el Estado, es permanente en la historia del capitalismo. Es uno de sus modos necesarios de acumulación que, según el periodo considerado, se distribuye de manera diferente entre las regiones industriales "nucleares" y la "periferia" colonizada. Por eso, debemos hablar de una acumulación primitiva permanente, que no es "primitiva" en absoluto, excepto en su representación ideológica. Hoy vemos claramente que dicha acumulación puede producir una especie de "colonización" de segundo grado en las antiguas metrópolis industriales, y poner fin a los sistemas de protección e integración social adquiridos para dar paso a formas de precariedad masiva que se pueden comparar a una "segunda ola" de proletarización. En todo el planeta, ahora encontramos destacamentos de "humanos desechables", una expresión que Bertrand Ogilvie ${ }^{13}$ usa para nombrar a los individuos producidos por la sociedad solo para ser utilizados como mano de obra barata y desechados después del uso en las formas convergentes de la miseria fisiológica, endémica guerra y, a veces, violencia genocida. Esto es también lo que en un poderoso ensayo Saskia Sassen ${ }^{14}$ ha llamado "expulsión": el capitalismo crea superpoblación solo para eliminarla o su "superávit". Sin embargo, como dije hace un momento, se crea una diferencia por la globalización en su etapa actual: la acumulación "primitiva" destruye y mata las afiliaciones personales, las solidaridades grupales y los lazos profesionales que otorgaban seguridad a los individuos, pero la globalización actual destruye sistemáticamente el medio ambiente. De hecho, esto comenzó hace mucho tiempo; fue un aspecto importante de la colonización y también estuvo involucrado en los modos productivistas de industrialización. Pero antes de la etapa actual, este proceso aún no amenazaba la estabilidad de los ecosistemas, ni las regulaciones geológicas y la diversidad de la vida en la tierra. Sabemos que esta violencia contra la naturaleza es también una forma extrema de violencia contra los seres humanos, que afecta sus formas de vida, su residencia en determinadas regiones del planeta, su identidad cultural y, en última instancia, su supervivencia. La globalización es también una gran transformación de las fuentes de acumulación de capital y formas de sujeción de los individuos, aprovechando la flexibilidad y fluidez del capital financiero para explotar a los humanos como productores y consumidores, como fuerza de trabajo y como aquellos con capacidad de sufrir y tener placer. Por tanto, surge una invasión de las necesidades y de los deseos más básicos de las personas. En otra obra escribí que la violencia "utilitaria" probablemente no es menos feroz que la violencia "totalitaria", incluso si tiene diferentes intenciones y distintos autores que permanecen esencialmente en el anonimato. ${ }^{15}$ La violencia extrema "utilitaria" que paradójicamente relega a millones

13 Bertrand Ogilvie, El hombre desechable: Ensayo sobre el exterminio y la violencia extrema. Traducido por Víctor Goldstein (Buenos Aires: Nueva Visión, 2013).

14 Saskia Sassen, Expulsiones: Brutalidad y complejidad en la economía global. Traducido por Stella Mastrangelo (Buenos Aires: Katz, 2015).

15 Balibar, Violence and Civility, 155. 
de vidas humanas a una condición de "de-utilidad" no es formalmente una violencia "soberana", sino más bien una forma cuasisoberana de violencia. Sus organizadores existen en forma de redes económicas y administrativas más que de gobernantes monárquicos o presidenciales, y sobre todo sus mecanismos de sometimiento incorporan permanentemente las propias necesidades y deseos de aquellos a quienes tienden a eliminar. Por esta razón, se puede llamar también alienación extrema.

Pero quizá hay un despliegue de violencia extrema que produce la eliminación de los humanos que es aún más perverso, en el sentido de que crea una "zona gris" donde los individuos no se distribuyen de manera preestablecida o predeterminada entre las dos categorías de víctimas y verdugos. Esta es también la razón por la que son inaccesibles a las intervenciones militares "humanitarias" (que la mayoría de las veces empeoran los conflictos más que cualquier otra cosa). Me refiero a formas de la llamada "violencia comunitaria", ya sea que se produzcan dentro o entre "comunidades" (religiosas, étnicas o raciales), categoría que, sin duda, es extraordinariamente vaga y discutible, pero cada vez más difícil de descartar. En mi libro, llamé ultraobjetiva a la violencia extrema del capitalismo y la globalización financiera, porque transforma a sus víctimas en utilidades desechables y ubica las responsabilidades en el nivel de procesos anónimos de acumulación. Por otro lado, sugerí que la violencia comunitaria es una forma de violencia ultraobjetiva, porque característicamente lo que ocurre no es realmente una intensificación de sentimientos de simpatía y antipatía vinculados a las instituciones de pertenencia y la membresía a identidades colectivas. Más bien, más allá de estos, se produce una sustitución que da lugar a una obsesión por la "pureza" grupal, que es por definición inaccesible y, por tanto, debe ser "verificada" mediante la eliminación de quienes portan cualquier marca de diferencia y alteridad, pero que también somete al terror a sus organizadores y verdugos. Se trata de una descripción especulativa, a través de la cual quiero indicar el grado de alienación del sujeto donde radica la violencia comunitaria, es decir, en la incorporación total de las personas (el "yo", el "tú") en un "nosotros" fetichizado o mítico (la famosa relación "amigo-enemigo"). Esto es lo que nos permite observar un "parecido familiar" entre los procesos de purificación (o "limpieza") que se realizan en nombre de la religión (o antirreligión) y los que se llevan a cabo en nombre de la raza o identidad étnica. Estos criterios pueden combinarse, por supuesto, como en el caso del pueblo rohinyá, entre varios otros en este momento, que son apuntados como musulmanes y como poblaciones supuestamente extranjeras. Lo mismo es rampante en Europa a una escala aún más amplia. Debemos inventar una metodología para analizar mejor qué cristaliza estos procesos heterogéneos, pero también, más allá de cualquier causalidad socioeconómica determinada, de repente produce las acciones asesinas en las que quienes matan y violan ya no pueden suspender sus inclinaciones, ni siquiera a costa de su propia consumación. Para nosotros, los europeos, esta cuestión se ha convertido en una cuestión candente desde las guerras en Yugoslavia o los ataques racistas a los migrantes, mientras que la xenofobia había sido oficialmente prohibida después de las trágicas experiencias del siglo XX. De manera más general, observamos en todas partes del mundo, tanto en el "viejo" como en el "nuevo", anteriormente colonizados y colonizadores, que las guerras de religión, aunque sobredeterminadas por otros factores, se están volviendo más frecuentes que nunca.

Por mi parte, nunca pensé que se pudiera aplicar una simple explicación o tipología. En Violence and Civility, inserté algunos diagramas que esencialmente buscan sugerir que hay un carácter intrínsecamente aleatorio en las combinaciones y formaciones de "comunidades" a través de la violencia. Debemos comenzar, me parece, con una reflexión sobre esta incertidumbre constitutiva, planteando preguntas para las que nunca habrá una respuesta clara. Primero, debemos preguntarnos si alguna vez existirá, esencialmente, algo parecido al odio comunitario puro, que podría aislarse de otros factores heterogéneos, en particular los económicos que surgen de la explotación, dominación y expropiación. Nótese que 
el odio del otro siempre afecta tanto a los "expropiadores" como a los "expropiados". Pero por mucho que creo que las metodologías reduccionistas, según las cuales las guerras de religión o la persecución racial solo pueden resultar de conflictos y contradicciones económicas desplazadas, son totalmente insuficientes, también estoy convencido de que la violencia comunitaria extrema nunca excede sus propios límites "normales" simplemente porque una lógica interna de fantasía identitaria o fanatismo ideológico la empuja en esa dirección. Las masacres y las persecuciones se montan en otro escenario; al menos los llamados "umbrales" de intolerancia entre poblaciones nunca se traspasan sin un desvío por el otro escenario. Esto es lo que observamos en este momento en Europa, donde vemos una combinación de desempleo, miedo a la descalificación profesional, obsesión por la seguridad y reacciones fóbicas a las diferencias culturales y religiosas encarnadas en refugiados y migrantes. Esencialmente, quiero decir que siempre se requiere una sobredeterminación de factores, y la composición de estos nunca es la misma. Pero se agrega un segundo elemento de incertidumbre e irracionalidad, que proviene del hecho de que la violencia comunitaria es siempre reactiva. Esta es una consideración peligrosa: lo que quiero decir es que la violencia comunitaria está ciertamente unida a las instituciones de lo común, o existe virtualmente donde la multiplicidad de individuos y grupos se reduce a un "nosotros" ontológico en la figura de una unidad transhistórica. Por eso, los nobles intentos de algunos filósofos contemporáneos de pensar el "ser en común" como una "comunidad sin comunidad", sin un principio de unidad sustancial o imaginario, siguen siendo políticamente tan problemáticos. Pero esto es demasiado abstracto para dar cuenta de la transgresión hacia la violencia extrema: debe haber algo así como una amenaza fantástica contra la comunidad, que puede basarse en procesos reales de descomposición de las formas tradicionales de solidaridad y afiliación (muy violentas), pero que los traspone a una fantasía de invasión o contaminación. Entonces, podemos observar una cadena de reacciones miméticas, especialmente cuando las comunidades que son perseguidas como "minorías" comienzan a buscar traidores internos, o desviados morales y culturales inaceptables entre ellas. En otros términos, lo que parece propio de la forma de comunidad es una capacidad singular de transmutar en instintos asesinos intensificados todas las exclusiones que a veces se producen en otro lugar o a las que están sometidos. Como si una comunidad fuera a la vez algo que implicaba una falta de existencia y coherencia, y que, por tanto, debiera buscar continuamente "complementos" de realidad, unidad e identidad, y algo que, paradójicamente, encontrará este complemento al restar, incluso amputar, una parte de sí misma que estaría en exceso: el hereje, el enemigo interno, el traidor, el ajeno, la minoría, el desviado. Repito: esta lógica no puede funcionar aisladamente, pero también es irreductible a otros determinismos.

Resumiré todo esto diciendo que observamos una superposición y un movimiento continuo de intercambios, en una economía de violencia generalizada, de violencia capitalista que se "libera" de sus regulaciones sociales, y violencia comunitaria y contraviolencia que exacerba fantásticamente su propia inseguridad, estando cada vez más expuesta a la diferencia y la disidencia. Esta situación se asemeja a un "estado de naturaleza" hobbesiano clásico, excepto que los ingredientes no son ideales, sino empíricos y observables, y de hecho no son naturales, sino completamente históricos y sociológicos, aunque escapan a las "leyes" aceptadas que gobiernan la composición de los grupos. Lo que pedía la imagen tradicional del "estado de naturaleza" hobbesiano para regular la violencia era la autoridad del Estado como sistema jurídico universal y la capacidad de "monopolizar" los instrumentos de coerción y fuerza. Esta era la figura de un poder público que no podía estar exento de fallas o desviarse de su función oficial, pero aparecía como el principal instrumento con el que los ciudadanos podían regular colectivamente las contradicciones sociales y "neutralizar" las pasiones ideológicas. Hay que proceder con mucho cuidado: ciertamente no pretendo excluir la posibilidad de que el Estado pueda desempeñar este papel, o que podamos necesitar usar su poder en situaciones de emergencia, o para contrarrestar ciertas formas 
de dominación adquirida, particularmente porque percibo que ciertas preguntas son urgentes: cómo transformar o transmutar los poderes públicos para que puedan operar en los ámbitos nacional, transnacional o cosmopolítico, y cómo lograr revoluciones que no supriman al Estado, de manera anarquista, sino que lo incorporen en sus mecanismos institucionales de autolimitación democrática. Precisamente por eso, sin embargo, me parece importante mostrar que el Estado es, en sí mismo, un factor de extrema violencia. Como consecuencia, su intervención con frecuencia no reduce la violencia; por el contrario, le añade un grado de intensidad y, sobre todo, la hace irreversible o "inconvertible" (expresión, tomada de Hegel, que utilicé en mi libro). Una vez más, nos enfrentamos a una ambivalencia intrínseca de los elementos que empujan la violencia, un elemento necesario de la política, a un extremo que hace que la política misma sea imposible.

Para llegar más directamente a mi punto principal, dejaré de lado la cuestión de los "micropoderes" y sus formas de crueldad cotidiana, a las que Foucault se adhirió particularmente: la crueldad de las cárceles, los tribunales, incluso los hospitales, las escuelas, por no hablar de las familias. Más bien, consideraré la capacidad de los micropoderes para revelar y multiplicar la violencia que pertenece propiamente al Estado como una unidad de poder centralizada y legítima. Debemos partir nuevamente de la consideración de esta unidad para comprender por qué hoy la idea de soberanía no es eliminada de la representación del Estado y sus operaciones, a pesar de cada "secularización" y "descentralización" de lo político, y por qué el poder estatal ha tenido una tendencia a intensificar su propia violencia tanto cuando es poderosa como cuando es impotente; y, no menos importante, por qué la propensión del Estado a la violencia extrema tiende a reproducirse en las mismas formas y fuerzas que desafían su poder, lo que en particular significa intentos de revolución. Mi primera tesis afirma que, de acuerdo con las antiguas mitologías del poder soberano, la "conversión" de la violencia en ley, o en instituciones, implica siempre un movimiento antitético que lo redobla, pero también lo contradice, por el cual la ley se convierte en violencia. Estamos tentados a creer que esto ocurre solo en circunstancias excepcionales como la guerra, la subversión o el terrorismo, pero la experiencia histórica más bien muestra que la excepción se expande y banaliza, de modo que los micropoderes y macropoderes del Estado están invadiendo continuamente el imperio de la ley y usándola, de hecho, para abolirla. No hay conversión jurídica de la violencia sin una conversión violenta de la ley. Esto es claramente visible en nuestros estados "posdemocráticos" en Europa hoy.

¿Por qué esta evolución? Nuevamente, nos sentimos tentados a invocar el sentido común, que no está del todo equivocado: el "monopolio" weberiano y hobbesiano del Estado, de hecho, sigue siendo impugnado mientras existan conflictos que no es capaz de resolver porque está al mismo tiempo siendo un juez y un participante. Tales son las luchas de clases y otras luchas en torno a los valores "morales" y la educación de los individuos. Esta podría ser casi una definición de "lucha de clases", válida en nuestro tiempo: una lucha de clases es una lucha en la que el Estado no puede ser neutral o estar por encima del conflicto. Solo puede fingir. Las operaciones del soberano son, por tanto, imperfectas y no "absolutas", y debe haber una tendencia a buscar poderes adicionales, que son las marcas visibles de la soberanía absoluta. Pero las más visibles de estas marcas son las formas de violencia y transgresión. Esto es muy claro en la descripción de Maquiavelo de la necesaria crueldad del príncipe. Sin embargo, creo que esta idea sigue siendo insuficiente, o que hay que llevarla más allá, hasta que nos planteemos la cuestión de la crueldad del Estado, cuyas causas no están en su poder, sino en su impotencia. Varios fenómenos contemporáneos llaman nuestra atención en esta dirección, en particular la creciente desproporción entre las capacidades del Estado para implementar sus políticas y las capacidades de los mercados financieros y sus operadores para ignorar y maniobrar en torno a estas políticas. En otro trabajo, sugerí que el síndrome de la "impotencia de los todopoderosos" es un determinante esencial del racismo institucional que 
podemos observar en nuestros Estados democráticos. Esto último es algo visible, por ejemplo, en las persecuciones contra los migrantes o los pueblos romaníes. ${ }^{16}$ Pero ahora quiero proponer otra idea: si el Estado es relativamente incapaz de controlar las actividades de los ciudadanos (o algunos de ellos), esto genera directamente una violencia específica en él. La forma más común, pero también más sorprendente, de esta violencia es la venganza del Estado contra quienes lo desafían o ignoran. Debemos tener cuidado de no atribuir "intenciones" imaginarias y motivos psicológicos a las estructuras e instituciones del Estado; pero, por otro lado, no podemos perder de vista el hecho incongruente de que una máquina jurídica e institucional que es impersonal siempre intenta promulgar venganza, más allá de la propia ley, contra las rebeliones a las que se enfrenta. Una vez más, podemos decir que esto surge de una fantasía, pero nos vemos obligados a admitir que existen fantasías colectivas y administrativas, por así decirlo, "sin sujeto", fantasías que, sin embargo, evocan una ultrasubjetividad del Estado de manera espectral. Si se trata de un fenómeno real (pensemos en Guantánamo, o el castigo de los "terroristas", incluido el Rote Armee Fraktion en Alemania, etc.), realmente podemos hablar de una patología del poder inherente a la forma estatal. Esto nos lleva a discutir la violencia revolucionaria como un fenómeno mimético con respecto a la violencia estatal, algo que creo que no es necesario demostrar. Experiencias trágicas han demostrado que esto suele conducir a la recuperación de aspiraciones revolucionarias al servicio de una restauración directa o indirecta del Estado. Pero lo que quizá sea más interesante es el hecho de que el fenómeno mimético surge al mismo tiempo de los dos lados opuestos: del poder de las revoluciones, que intentan igualar el "monopolio de la violencia legítima" del Estado (su "conservadora violencia", según Benjamin $)^{17}$ con el monopolio de la violencia subversiva (o "divina"), y de la falta de poder de las revoluciones cuando se muestran incapaces de superar políticamente obstáculos internos y externos, genéricamente etiquetados como "fuerzas contrarrevolucionarias", que las llevan a reprimir a las mismas personas que pretenden emancipar, una trágica combinación de mimetismo con el Estado y la violencia "comunitaria".

Teniendo muy poco espacio para tratar de desarrollar la contraparte, lo que he llamado tentativamente una estrategia o política de antiviolencia o civilidad, terminaré de una manera muy alusiva. Permítanme volver a mi primera proposición, cuando dije que la violencia extrema era una cuestión de vida o muerte para la política. Parece haber una tautología en esta formulación: si se produce una violencia extrema, la política puede desaparecer, o quizá ha desaparecido, a menos que encuentre recursos para su propia resurrección cuando llegue al límite. Esto significaría, más bien, que los individuos y los grupos son capaces de recrear la política y de recrearse a sí mismos como sujetos políticos, sépase, como actores políticos. Recordamos los famosos versos del poema de Hölderlin "Patmos": "Wo aber Gefahr ist, wächst / das Rettende auch" ("Pero donde haya peligro / crece lo que nos salva"). ${ }^{18}$ Esta fórmula tiene claramente una dimensión mesiánica, que quiero evitar, porque creo que no es el peligro como tal lo que hipotética y milagrosamente genera el advenimiento de la

16 Étienne Balibar, “De la préférence nationale à l'invention de la politique”. En Droit de cité (París: Presses universitaires de France, 1998), 109; Étienne Balibar, "Populism in the American Mirror", Verso, 10 de enero de 2017, https://www. versobooks.com/blogs/3039-etienne-balibar-populism-in-the-american-mirror.

17 Walter Benjamin, "Para una crítica de la violencia”, en Ilustraciones IV: Para una crítica de la violencia y otros ensayos. Traducido por Roberto Blatt (Madrid: Taurus, 2001), 9-22.

18 Friedrich Hölderlin, "Patmos”, en Poesía completa. Edición bilingüe. Traducido por Federico Gorbea (Barcelona: Ediciones 29, 1995), 395. 
redención o de un redentor. Solo puede ser una combinación de reflexión y pasión, comprensión de la situación, consciencia de lo que está en juego, capacidad de decisión y solidaridad colectiva; en resumen, lo que en circunstancias similares Maquiavelo llamaría "virtud" en el sentido antiguo, o acción en el sentido fuerte, que él sabía que era extremadamente improbable. Sin embargo, tal virtud o capacidad de acción se hace visible solo después del evento, a través de sus propios efectos; por tanto, volvemos a la pregunta: ¿hubo alguna vez civismo en la historia, en forma de revoluciones, fundamentos institucionales, mediaciones, hegemonías, siempre singulares? Me atrevo a decir que sí, incluso que siempre ha existido desde que ha existido la política, en formas que no se pueden imitar, pero que siguen siendo fuente de inspiración. Podemos ver, sin embargo, que tales formas o "estrategias" implican siempre una condición paradójica: deben presuponer su propio resultado, es decir, contar con fuerzas cuya condición de posibilidad es su propio devenir, como si anticiparan su propia realización. Lo que también significa: corren el riesgo de equivocarse en el momento y la objetividad, lo que prácticamente significa el riesgo de agravar las situaciones de violencia. Esta es la diferencia absoluta entre la política de civismo en la historia y la implementación de la ley, el seguimiento de una regla, ya sea establecida, ya sea imaginada. La política es siempre aleatoria. Hace planes o "proyectos", pero nunca se planifica.

A esta tesis especulativa general agregaré otra determinación. Es útil retener la tipología de formas de violencia extrema que propuse antes. Por tanto, sugiero que las estrategias de civilidad son la contraparte exacta de las modalidades dominantes de violencia extrema. Así, si el capitalismo en el momento de su globalización financiarizada produce una reversión de la utilidad a una forma radical de "de-utilidad", debemos intentar elaborar una política de uso y usos, que no sea solo una "economía" de recursos naturales y tecnológicos, sino una forma de usar (o usar bien) a los propios seres humanos, como cuerpos y almas. ${ }^{19}$ Por tanto, no se trata tanto de respetar abstractamente a sus personas, como se indica en Kant o en las famosas declaraciones universales de derechos humanos, que tienen su valor. Es más bien, en el espíritu de la fórmula de Spinoza, que "nada hay, pues, más útil para el hombre que el hombre": para todo ser humano, debe existir la posibilidad de ser supremamente útil, de "hacer uso" de sus posibilidades. ${ }^{20}$ Por otro lado, si las formas de violencia comunitaria, con sus múltiples causas y circunstancias, implican siempre la intención de "depurar" una identidad común, debemos imaginar políticas que no solo estén a favor de la diferencia, sino también de la hibridación o metamorfosis, y proporcione medios para tomar distancia, incluso, del compromiso mismo, o de la "fe" y las convicciones sin las cuales no existe una práctica política real. En este punto concreto, podemos ver perfectamente por qué la proposición debe ser circular: porque el obstáculo mismo que hay que superar en común es la primacía del Uno. Sin embargo, también sabemos que esta primacía es constantemente desafiada por elementos externos entrantes; "extraños" que, por así decirlo, nos ofrecen la civilidad como una posibilidad, a través de su mera presencia. Finalmente, si la violencia mimética del Estado y las revoluciones produce el abismo en el que se pierden los intentos de "cambiar el mundo", podemos decir que perturbar la relación especular entre Estado y revolución, encontrar una línea de escape para la política revolucionaria que involucra su propio "proceso civilizador", es otra forma de denominar esta circularidad. Esto es algo que también se podría formular en el lenguaje de la conducta y el uso del conflicto. La "amenaza mortal” de la violencia

19 Para esto estoy pensando en Giorgio Agamben, El uso de los cuerpos: Homo sacer IV, 2. Traducción de Rodrigo Molina-Zavalía (Buenos Aires: Adriana Hidalgo, 2017).

20 Baruch Spinoza, Ética demostrada según el orden geométrico. Traducido por Pedro Lomba (Madrid: Trotta, 2000$), 197$. Esta es una traducción modificada. 
extrema para la política no es la amenaza del conflicto como tal, ni siquiera del conflicto "radical"; al contrario, es la amenaza de aniquilación del conflicto y la posibilidad de utilizarlo para eliminar obstáculos económicos y sociales, para cambiar las relaciones de fuerzas. Por tanto, debemos expandir la democracia misma, tratando de encontrar la "medida justa" de agonismo y antagonismo entre las formas puramente cosméticas del pluralismo representativo, en las que los intereses se reducen a opiniones, y a las modalidades nihilistas de la guerra civil. Por supuesto, lo que estoy sugiriendo no es una simple inversión de las fórmulas kantianas, en las que la "paz perpetua" surge de la implementación de la hospitalidad y el comercio. No estoy proponiendo que reemplacemos esto con la idea de "conflicto perpetuo", por así decirlo. Estoy tratando de encontrar una idea más sutil por la cual la civilidad emerja como una capacidad para actuar en los conflictos y sobre ellos, una capacidad para participar en los conflictos de tal manera que sus condiciones se transformen. Aquí es donde están en juego las posibilidades de establecer una comunicación entre la reflexión, el compromiso individual y la construcción de un poder colectivo, así como las posibilidades de revertir la servidumbre voluntaria en el empoderamiento de los individuos que actúan contra el statu quo y la fatalidad.

Tomando estas expresiones en conjunto, ¿no nos estamos acercando precisamente a una definición de política, o una forma de "practicarla", no como un mero uso contingente de la violencia, sino como una forma consciente de "antiviolencia"?

\section{Bibliografía}

Agamben, Giorgio. El uso de los cuerpos: Homo sacer IV, 2. Traducción de Rodrigo Molina-Zavalía. Buenos Aires: Adriana Hidalgo, 2017.

Althusser, Louis. "Defensa de tesis en Amiens". En Posiciones. Traducción de Ricardo Pochtar, 127-172. Barcelona: Anagrama, 1977.

Arendt, Hannah. La vida del espíritu: El pensar, la voluntad y el juicio en la filosofía y en la política. Traducido por Ricardo Montoro y Fernando Vallespín. Madrid: Centro de Estudios Constitucionales, 1984.

Balibar, Étienne. De la préférence nationale à l'invention de la politique. En Droit de cité, 89-132). París: Presses universitaires de France, 1998.

Balibar, Étienne. Masses, Classes, Ideas: Studies on Politics and Philosophy Before and After Marx. Nueva York: Routledge, 1994.

Balibar, Étienne. "Populism in the American Mirror". Verso, 10 de enero de 2017. https://www.versobooks.com/ blogs/3039-etienne-balibar-populism-in-the-american-mirror.

Balibar, Étienne. Violence and Civility: On the Limits of Political Anthropology. Traducido por G. M. Goshgarian. Nueva York: Columbia University Press, 2014.

Benjamin, Walter. "Para una crítica de la violencia". En Ilustraciones IV: Para una crítica de la violencia y otros ensayos. Traducido por Roberto Blatt. 9-22. Madrid: Taurus, 2001.

Hölderlin, Friedrich. "Patmos". En Poesía completa. Edición bilingüe. Traducido por Federico Gorbea, 395-408. Barcelona: Ediciones 29, 1995.

Foucault, Michel. Vigilar y castigar: Nacimiento de la prisión. Traducido por Aurelio Garzón del Camino. Buenos Aires: Siglo XXI, 2003.

Foucault, Michel. Defender la sociedad: Curso en el Collège de France (1975-1976). Traducido por Horacio Pons. Buenos Aires: Fondo de Cultura Económica, 2001.

Ogilvie, Bertrand. El hombre desechable: Ensayo sobre el exterminio y la violencia extrema. Traducido por Víctor Goldstein. Buenos Aires: Nueva Visión, 2013.

Rancière, Jacques. El reparto de lo sensible: Estética y política. Traducido por Cristóbal Durán, Helga Peralta, Camilo Rossel, Iván Trujillo y Francisco de Undurraga. Santiago de Chile: LOM, 2009. 
Sassen, Saskia. Expulsiones: Brutalidad y complejidad en la economía global. Traducido por Stella Mastrangelo. Buenos Aires: Katz, 2015. https://doi.org/10.2307/j.ctvm7bdqr

Schmitt, Carl. El nomos de la tierra: En el derecho de gentes del "Jus publicum europaeum". Traducido por D. Schilling. Buenos Aires: Struhart, 2005.

Spinoza, Baruch. Ética demostrada según el orden geométrico. Traducido por Pedro Lomba. Madrid: Trotta, 2000.

Weil, Simone. "La Ilíada o el poema de la fuerza". En La fuente griega. Traducido por M. E. Valentié, 13-44. Buenos Aires: Sudamericana, 1961. 